\title{
Cytomegalovirus prevalence in pregnant women: the influence of parity
}

\author{
Pat A Tookey, Anthony E Ades, Catherine S Peckham
}

\begin{abstract}
Over 20000 women attending for antenatal care at three London hospitals were prospectively studied to determine the prevalence of cytomegalovirus (CMV) antibodies; $54.4 \%$ of these women were CMV seropositive. Ethnic group was strongly associated with CMV status: $45.9 \%$ of white women were seropositive, $88 \cdot 2 \%$ of Asian, and $77 \cdot 2 \%$ of black women (African/Caribbean ethnic origin). Among 12159 white women born in the British Isles, seropositivity was independently associated with increasing parity, older age, lower social class, and being single at antenatal booking. The findings are consistent with the hypothesis that, in the UK, child to mother transmission of infection plays a significant part in the acquisition of CMV infection in adult life.
\end{abstract}

Cytomegalovirus (CMV) is common worldwide and a well recognised cause of handicap in infants born with congenital infection. The majority of congenitally infected infants develop normally, but about $10 \%$ are likely to have permanent $\mathrm{CMV}$ related damage, ranging from unilateral sensorineural hearing loss to multiple disabilities which can include microcephaly, cerebral palsy, sensorineural hearing loss, impaired vision, and mental retardation. ${ }^{1}$

Congenital infection can follow either primary or recurrent maternal infection, but the likelihood of fetal infection and the risk of associated damage is higher after a primary infection. ${ }^{2} 3$ In developing countries, where most people acquire CMV infection in early childhood, most congenital infections follow maternal recurrent infection. In the UK, although acquisition of $\mathrm{CMV}$ infection in infancy is common (largely attributable to transmission from seropositive mothers at delivery or through breast feeding ${ }^{4}$ ), more than $60 \%$ of women reach adult life still susceptible to CMV and about three quarters of congenital infections are likely to be attributable to primary maternal infection. ${ }^{5}$

Sexual transmission is acknowledged to play an important part in the acquisition of CMV infection in adult life. ${ }^{67}$ Studies in the USA examining the transmission of CMV in day nurseries have suggested that children may also be an important source of infection for their mothers or other caretakers. ${ }^{8} 9$ The relative importance of contact with children in comparison with other modes of transmission of infection in adult life is unclear and will depend on a number of factors relating to breastfeeding, sexual and child rearing practices, which vary considerably between countries and social and ethnic groups. The relative importance of different modes of transmission of CMV in the UK is unknown, although there is some anxiety about the possibility of occupational risk for women working with young children. ${ }^{10}$

The present analysis is based on data collected as part of a large prospective study of CMV infection in pregnancy carried out in west London between 1980 and 1986. The main aims of the study were to examine the CMV serological status of women booking for antenatal care, estimate the incidence of congenital CMV infection, and investigate its long term sequelae. ${ }^{3}$ This paper explores the independent effects of social class, marital status, age, and parity on maternal seroprevalence at antenatal booking.

\section{Subjects and methods}

All women booking for antenatal care at three west London hospitals were eligible for enrolment in the study, which continued for one year at the first hospital, two years at the second, and six and a half years at the third. Details of maternal age, parity, marital status, country of birth, race, and both maternal and paternal occupation were collected by interview at the first antenatal appointment, together with a blood sample to establish CMV serological status. Sera were tested for CMV antibodies by complement fixation, and detection of specific antibody at a dilution of 1:10 was taken to indicate past CMV infection. While this assay may be less sensitive than others now available, it is acceptable for epidemiological purposes; any slight inaccuracy in the overall estimation of seroprevalence will not affect the internal comparison of results presented here.

Analysis of the whole dataset was carried out using SAS. ${ }^{11}$ A grouped binomial relative risk regression ${ }^{12}$ was performed on a subset of the data, white women born in the British Isles, to explore the independent roles of parity, marital status, social class, and age.

Women were assigned to five parity groups, ranging from those who had no previous children to those who had four or more. Two marital status groups were defined: one comprising women who were married or cohabiting at the time they booked for antenatal care, and the second those who were single, divorced, widowed, or separated (hereafter referred to as 
single). Social class was categorised by partner's occupation for married and cohabiting women, and by their own occupation for single women, ${ }^{13}$ and was then divided into four occupational groups: professional (Registrar General's social class I and II), clerical (III non-manual), manual (III manual, IV, and V), and unclassified (unemployed, students, housewives, and armed forces). Finally, the mean age of each subgroup of women was calculated and used as the age value of that subgroup in the regression.

\section{Results}

Altogether 21882 women who booked consecutively for antenatal care were enrolled into the study. Many of these women booked for more than one pregnancy during the study period, but only the first pregnancy in which a blood sample was collected was included in this analysis; the CMV serological status of 20684 women $(94.5 \%)$ was known.

The overall CMV seroprevalence was $54.4 \%$, but the study population was ethnically diverse and ethnic group was strongly associated with seroprevalence, Asian women having the highest level, $88 \cdot 2 \%$, and white women the lowest, $45.9 \%$ (table 1). There were marked differences in both seroprevalence and demographic characteristics between women of the same ethnic group who were born in different countries. In addition, British born women of all ethnic groups were less likely to be seropositive than those born elsewhere, and also tended to be younger and more often single. It is likely that family structure and organisation, and arrangements for the care of young children, also varied between the different groups.

The complex relationship of age, parity, social class, marital status, and CMV seroprevalence was therefore explored in the homogeneous subgroup of this London population, the 12559 white women born in the British Isles. The overall CMV seroprevalence in this subgroup was $42 \cdot 8 \%$. As shown in table 2, there was a clear trend of rising seroprevalence with increasing age from $36.6 \%$ in those under 20 years to $51.4 \%$ in women aged 35 and over, and with increasing parity from $38.9 \%$ in nulliparous women to $66.2 \%$ in women expecting their fifth or subsequent child. Single women were more likely to be seropositive than those with a partner, and the lower the social class the higher the proportion of seropositive women.

The figure shows the CMV seroprevalence by age and parity. While there was a steady and gradual rise in seropositivity with age for

Table 1 Ethnic group and CMV seroprevalence

\begin{tabular}{lll}
\hline $\begin{array}{l}\text { Ethnic group } \\
\text { (No in group) }\end{array}$ & $\begin{array}{l}\text { Seroprevalence } \\
(\%)\end{array}$ & $\begin{array}{l}95 \% \text { Confidence } \\
\text { interval (\%) }\end{array}$ \\
\hline Asian (1939) & $88 \cdot 2$ & $86 \cdot 8$ to $89 \cdot 7$ \\
Black (1972) & $77 \cdot 2$ & $75 \cdot 3$ to 79.0 \\
Oriental (533) & 83.9 & $80 \cdot 7$ to 87.0 \\
White (15 586) & 45.9 & $45 \cdot 1$ to 46.7 \\
Other (157) & 58.0 & $50 \cdot 2$ to 65.7 \\
& & 53.6 to 55.0 \\
\hline
\end{tabular}

Table $2 C M V$ seroprevalence and age group, parity, marital status, and social class in 12559 white women born in the British Isles

\begin{tabular}{|c|c|c|}
\hline & $\begin{array}{l}\text { Seropositive } \\
(\%)\end{array}$ & $\begin{array}{l}\text { 95\% Confidence } \\
\text { interval (\%) }\end{array}$ \\
\hline $\begin{array}{l}\text { Overall } \\
\text { Age group (years): }\end{array}$ & $42 \cdot 8$ & 41.9 to 43.7 \\
\hline $\begin{array}{l}\text { Age group (years): } \\
<20 \\
20-24 \\
25-29 \\
30-34 \\
35+ \\
\text { Paty }\end{array}$ & $\begin{array}{l}36 \cdot 6 \\
39 \cdot 8 \\
41 \cdot 7 \\
44 \cdot 5 \\
51 \cdot 4\end{array}$ & $\begin{array}{l}33.6 \text { to } 39 \cdot 7 \\
37.9 \text { to } 41 \cdot 7 \\
40 \cdot 2 \text { to } 43.2 \\
42 \cdot 8 \text { to } 46.0 \\
48 \cdot 8 \text { to } 54 \cdot 1\end{array}$ \\
\hline Parity group: & & \\
\hline $\begin{array}{l}0 \\
1 \\
2 \\
3 \\
4+\end{array}$ & $\begin{array}{l}38 \cdot 9 \\
46 \cdot 4 \\
49 \cdot 5 \\
55 \cdot 4 \\
66 \cdot 2\end{array}$ & $\begin{array}{l}37.8 \text { to } 40.0 \\
44.7 \text { to } 48 \cdot 1 \\
46 \cdot 7 \text { to } 52 \cdot 4 \\
50.3 \text { to } 60.5 \\
58.9 \text { to } 73.6\end{array}$ \\
\hline Marital status: & & \\
\hline $\begin{array}{l}\text { Single } \\
\text { Married/cohabiting }\end{array}$ & $\begin{array}{l}46 \cdot 9 \\
41 \cdot 9\end{array}$ & $\begin{array}{l}44.8 \text { to } 49 \cdot 0 \\
40.9 \text { to } 42 \cdot 9\end{array}$ \\
\hline $\begin{array}{l}\text { Social class: } \\
\text { Professional } \\
\text { Clerical } \\
\text { Manual } \\
\text { Unclassified }\end{array}$ & $\begin{array}{l}40 \cdot 0 \\
43 \cdot 5 \\
45 \cdot 2 \\
45 \cdot 5\end{array}$ & $\begin{array}{l}38.7 \text { to } 41.4 \\
41.3 \text { to } 45.6 \\
43.6 \text { to } 46.9 \\
43.1 \text { to } 47.9\end{array}$ \\
\hline
\end{tabular}

nulliparous women, this was not the case for parous women. The more children a woman already had, the higher the probability of being seropositive, and the smaller the effect of increasing age. Indeed, younger women of high parity were more likely to be seropositive than older women. This suggests that there is a particularly high rate of acquisition of $\mathrm{CMV}$ infection in young parous women.

To estimate the independent effects and thus the relative importance of age, parity, marital status, and social class, a binomial relative risk regression was carried out on the $12159(96.8 \%)$ members of the subgroup for whom all the variables of interest were available.

Two models were fitted: in the first, all four variables were categorical; and in the second, social class and marital status were categorical, and age and parity continuous. The first model accounted for slightly more of the variance than the second, but the difference between the two was not significant at the 5\% level; the second model was therefore used so that age and parity effects could be estimated per year of age and per previous child born. The possibility that there might be interaction between the factors was explored. The only statistically significant interaction was that between age and parity, with parity having a greater effect on seroprevalence in younger

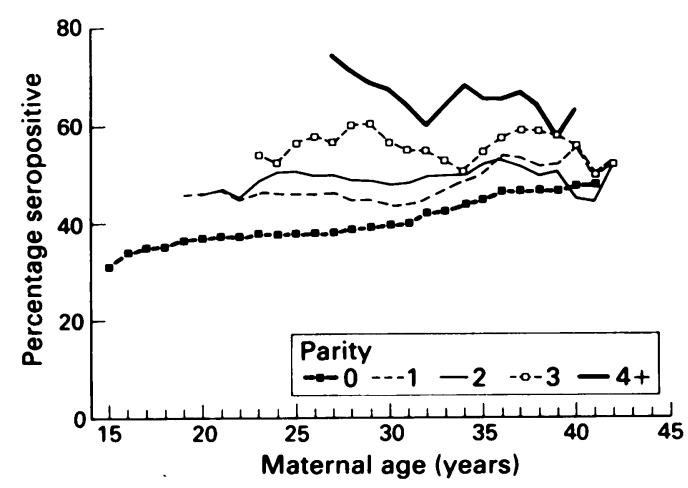

Seroprevalence of CMV in 12559 white women born in the British Isles and attending for antenatal care in west London 1980-6 (five year rolling averages). 
Table 3 Logistic regression for 12159 white women born in the British Isles, showing log likelihood $\chi^{2}$ tests and estimated relative risks

\begin{tabular}{|c|c|c|c|c|}
\hline & $\chi^{2}$ & $d f$ & Relative risk & $95 \%$ Confidence interval \\
\hline Age (per 5 years) & $68 \cdot 1^{*}$ & 1 & $1 \cdot 117$ & 1.09 to 1.15 \\
\hline Parity (per baby) & $70 \cdot 9 *$ & 1 & $1 \cdot 140$ & $1 \cdot 11$ to $1 \cdot 18$ \\
\hline Social class: & $35 \cdot 3^{*}$ & 3 & & \\
\hline Professional & & & 1 & \\
\hline Clerical & & & $1 \cdot 102$ & 1.04 to 1.17 \\
\hline Manual & & & $1 \cdot 166$ & 1.11 to 1.23 \\
\hline Unclassified & & & $1 \cdot 128$ & 1.05 to 1.21 \\
\hline Marital status: & 45.9* & 1 & & \\
\hline $\begin{array}{l}\text { Married/cohabiting } \\
\text { Single }\end{array}$ & & & 1.233 & 1.17 to 1.30 \\
\hline $\begin{array}{l}\text { Single } \\
\text { Age (per } 5 \text { years, }\end{array}$ & & & & 1210100 \\
\hline per baby) & $9 \cdot 3^{* *}$ & 1 & 0.973 & 0.96 to 0.99 \\
\hline
\end{tabular}

Baseline CMV seroprevalence $33.05 \%$ (95\% confidence interval $31 \cdot 6 \%$ to $34 \cdot 5 \%$ )

(nulliparous, age 25, married, professional social class).

*Extra deviance to remove from model with main effects only.

***Extra deviance to add to main effects model.

women than in older women; this term was therefore added to the model.

Table 3 shows the $\chi^{2}$ value, relative risk for seropositivity for each factor, and its $95 \%$ confidence interval; the $\chi^{2}$ value tests the statistical significance of each factor when the others are held constant. Age and parity were most strongly associated with seroprevalence, followed by marital status, and then social class.

The risk of being seropositive increases with each successive child. A 25 year old woman having her second child is an estimated $1 \cdot 14$ times more likely than a nulliparous woman of the same age to be seropositive, if she is having a third child this increases to $1 \cdot 3\left(1 \cdot 14^{2}\right)$ and for her fourth to $1.48\left(1 \cdot 14^{3}\right)$. Because of the negative interaction between age and parity, the increased risk associated with higher parity is less in older women. For a woman aged 35, the corresponding figures relative to a nulliparous woman aged 35 are $1.08,1.16$ and 1.26 (for instance the latter is $\left.1 \cdot 14^{3} \times\left(0.973^{2}\right)^{3}\right)$.

This can be compared with the relative risks for the other factors: a 30 year old nulliparous woman is estimated to be 1.12 times more likely to be seropositive than a 25 year old nulliparous woman of the same marital status and social class; a woman who works (or whose partner works) in a manual occupation is 1.17 times more likely than a professional woman to be seropositive; a single woman is 1.23 times more likely than a married or cohabiting woman to be seropositive. The relative risks combine multiplicatively, so a single 25 year old woman with one child is 1.41 $(1 \cdot 14 \times 1 \cdot 233)$ times more likely than a nulliparous married 25 year old of the same social class to be seropositive.

\section{Discussion}

The epidemiology of CMV in a particular population, and the relative importance of different modes of transmission, are likely to be determined by cultural practices relating to breast feeding, ${ }^{4} 14$ child rearing, child care arrangements, ${ }^{15}$ and sexual behaviour. ${ }^{616-18}$

Ethnic group was an important determinant of CMV seroprevalence in this London population. Women who were born in countries where CMV seroprevalence is high at young ages (for instance, parts of Africa, ${ }^{19}$ South
America, ${ }^{20}$ Asia, ${ }^{21}$ and southern Europe ${ }^{22}{ }^{23}$ ) had rates of seroprevalence which probably reflected their acquisition of infection in infancy and childhood. Similar observations have been made in other studies carried out among ethnically diverse populations. ${ }^{24-27}$

In order to explore the independent effects of social class, marital status, age, and parity, a restricted analysis was undertaken of the factors associated with seropositivity in a homogeneous subgroup with a high proportion of women susceptible to primary CMV infection during their childbearing years: approximately 12500 white British born women. Each of the four factors, parity, age, social class, and marital status, had a strong independent association with CMV seroprevalence.

The independent association of parity with seroprevalence, having controlled for the other factors, was particularly striking. In all age groups women of higher parity were more likely to be seropositive than those having their first or second child.

This effect of parity among women of the same age could be accounted for by child to mother transmission of infection, from children who had themselves acquired infection from elsewhere. A number of nursery studies have documented child to child transmission of infection, and examples of children and nursery staff sharing the same virus strain have been identified. ${ }^{28-30}$ Studies in the USA have found high rates of seroconversion among some day care workers, ${ }^{31-33}$ and children who acquire infection in day nurseries have been shown to transmit infection to their susceptible mothers, ${ }^{15}$ as have infants who were infected through blood transfusion. ${ }^{8}$

Several other studies have observed an association between parity and CMV status. A longitudinal study in a middle class population in Houston, USA, ${ }^{34}$ found that the presence of young children in the home was a risk factor for primary infection in pregnancy, and that maternal seropositivity was associated with the presence of older children. ${ }^{26}$ The Alabama group also observed a rising seroconversion rate with subsequent pregnancies in a high socioeconomic group. ${ }^{35}$

An alternative, or additional, explanation for the association of parity and seroprevalence could be that women who have had more pregnancies have also, on average, had more previous sexual partners. In an evaluation of the relationship between sexual practices and CMV seroprevalence among women in Seattle, USA, ${ }^{7}$ sexual activity was an important determinant of seropositivity, but the association was stronger for white than for black women, and in addition, parity was associated with seropositivity in the white but not in the black women.

Much of the crude effect of age on seroprevalence was accounted for by parity, but even after controlling for the other factors a major independent age effect remained. A relatively high incidence of primary infection in infancy is probably followed by a lower incidence through childhood, which increases in adolescence with the onset of sexual activity. 
Tempting though it is to attribute the rise in seropositivity with increasing age to the acquisition of infection in adult life, this interpretation of cross sectional age specific seroprevalence data could be misleading. Different birth cohorts of women may have experienced different rates of acquisition of infection in infancy, adolescence, and adult life as a result of changing patterns of breast feeding and sexual activity.

Infants born to seropositive women may acquire CMV infection during delivery, ${ }^{36}{ }^{37}$ or through breast feeding; ${ }^{14}$ currently approximately $20 \%$ of children born in Britain are likely to be seropositive by the age of 12 months. ${ }^{4}$ Virtually all women enrolled in this study were born between 1935 and 1970, a period which saw an appreciable decline in breast feeding. Until the 1930 s most children were breast fed for several months, but by 1946 only $45 \%$ of British babies were still breast fed at the age of 2 months, ${ }^{38}$ and by 1970 this had declined to only $30 \%$ at the end of the first week. ${ }^{39} \mathrm{CMV}$ is more likely to be present in breast milk after the first week than before, and colostrum is a relatively poor source of virus. ${ }^{40}$ It is therefore likely that some of the apparent effect of increasing age in this population is related to lower levels of $\mathrm{CMV}$ infection in infancy in the younger women.

Age at first sexual intercourse, number of sexual partners, and the use of barrier methods of contraception have all been associated with CMV seroprevalence, ${ }^{7}$ and are also factors which are likely to show both a cohort effect and social class differences.

This analysis demonstrated an interaction between parity and age, in that the association of high parity with seropositivity was greater in younger women than in those who were older. Indeed, women who were pregnant with a fifth child by their mid to late 20 s were more likely to be seropositive than older women of high parity, who had presumably either spaced their children out more, or started having them later.

Several studies have shown an association between seroprevalence and social class, ${ }^{35} 41$ and some studies of seroconversion in pregnancy have been restricted to higher socioeconomic groups in order to enrol a relatively high proportion of seronegative women. It is possible that single pregnant women have had, on average, a greater number of sexual partners than married or cohabiting pregnant women, and this could, to some extent, account for the association of single status with seropositivity. However, seroprevalence may be associated with child care arrangements, as discussed above, and use of day care is strongly influenced by both social class and marital status, as well as maternal age and most obviously parity. In most of the UK, and certainly in the London area from which the study population was drawn, access to day care facilities is highly dependent on family situation and socioeconomic status. Women of low socioeconomic status are more likely than professional women to have their children cared for in day nurseries; single women and very young women, particularly those who have several children, are also more likely to use these facilities.

\section{Conclusion}

Within each age band and social class group, women with children are likely to differ from those without children, and it is difficult, using cross sectional data, to disentangle the effects of social and cohort factors, such as child care arrangements, breast feeding experience, and sexual history. None the less, in this study the independent effect of parity, having allowed for age, social class, and marital status, was very striking and certainly consistent with the hypothesis that children are an important source of infection for their susceptible mothers.

We thank the medical, nursing, and clerical staff and the women attending for antenatal care at Charing Cross (West London Hospital), Central Middlesex, and Queen Charlotte's Hospitals during the study period, and also the laboratory staff, in particular Mr Kong Shin Chin. We also thank Dr Stuart Logan for his helpful comments.

This work was supported by grants from the National Fund for Research into Crippling Diseases, the Medical Research Council, and the Child Health Research Appeal Trust.

1 Best JM. Congenital cytomegalovirus infection. $B M \mathcal{F}$ 1987;294:1440-1.

2 Ahlfors K, Ivarsson S-A, Harris S, et al. Congenital cytomegalovirus infection and disease in Sweden and the relative importance of primary and secondary maternal infections: preliminary findings from a prospective study. Scand $\mathcal{F}$ Infect Dis 1984;16:129-37.

3 Peckham CS, Chin KS, Coleman JC, Henderson K, Hurley R, Preece PM. Cytomegalovirus infection in preg nancy: preliminary findings from a prospective study. Lancet 1983;i:1352-5.

4 Peckham CS, Johnson C, Ades A, Pearl K, Chin KS. Early acquisition of cytomegalovirus infection. Arch Dis Child 1987;62:780-5.

5 Preece PM, Pearl KN, Peckham CS. Congenital cytomegalovirus infection. Arch Dis Child 1984;59:1120-6.

6 Handsfield $\mathrm{HH}$, Chandler SH, Caine VA, et al. Cytomegalovirus infection in sex partners: evidence for Cytomegalovirus infection in sex partners: eviden

7 Collier AC, Handsfield HH, Roberts PL, et al. Cytomegalovirus infection in women attending a sexually megalovirus infection in women disease clinic. $\mathcal{f}$ Infect $D$ is 1990;162:46-51.

8 Yeager A. Transmission of cytomegalovirus to mothers by infected infants: another reason to prevent transfusionacquired infections. Pediatr Infect Dis 1983;2:295-7.

9 Adler SP. Molecular epidemiology of cytomegalovirus: viral transmission among children attending a day care center, their parents, and caretakers. $\mathcal{F}$ Pediatr 1988;112:366-72.

10 Tookey P, Peckham CS. Does cytomegalovirus present an occupational risk? Arch Dis Child 1991;66:1009-10.

11 SAS Institute Inc. SAS user's guides. Version 5 edition. USA, 1985.

12 Wacholder S. Binomial regression in GLIM: estimating risk ratios and risk differences. Am $\mathcal{f}$ Epidemiol 1986;123: ratios and

13 Office of Population Censuses and Surveys. Classification of occupations. London: HMSO, 1980.

14 Stagno S, Reynolds DW, Pass RF, Alford CA. Breast milk and the risk of cytomegalovirus infection. $N$ Engl $f$ Med 1980;302:1073-6.

15 Adler SP. Cytomegalovirus transmission among children in day care, their mothers and caretakers. Pediatr Infect Dis 1988;7:279-85.

16 Davis LE, Stewart JA, Garvin S. Cytomegalovirus infection: a seroepidemiologic comparison of nuns and women from a venereal disease clinic. Am $\mathcal{F}$ Epidemiol 1975;102 327-30.

17 Chandler SH, Holmes KK, Wentworth BB, et al. The epidemiology of cytomegaloviral infection in women attending a sexually transmitted disease clinic. $\mathcal{F}$ Infect Dis 1985;152:597-605.

18 Chretien J, McGuinness C, Muller A. Venereal causes of cytomegalovirus mononucleosis. $7 A M A$ 1977;238:1644-5.

19 Schopfer K, Lauber E, Krech U. Congenital cytomegalovirus infection in newborn infants of mothers infected before pregnancy. Arch Dis Child 1978;53:536-9.

20 Linhares MS, Andrade GP, Coelho AF, Tateno S, Eizuru Y, Minamishima Y. Prevalence of cytomegalovirus antiY, Minamishima Y. Prevalence of cytomegalovirus antiborns. Acta Paediatr fpn 1989;31:620-2.

21 Liu Z, Wang E, Taylor W, et al. Prevalence survey of 
cytomegalovirus infection in children in Chengdu. Am $\mathfrak{f}$ Epidemiol 1990;131:143-50.

22 Hayes $K$. Prenatal viral infection with particular reference to cytomegaloviruses. Australian Paediatric fournal 1974; 10:56-63.

23 Volpi A, Pica F, Cauletti M, Pana A, Rocchi G. Cytomegalovirus infection in day care centers in Rome, Italy: viral excretion in children and occupational risk among workers. f Med Virol 1988;26:119-25.

24 Urkin J, Sarov B, Naggan L, Haikin H, Sarov I. Prevalence of cytomegalovirus antibodies among women of childbearing age in different social environments in southern Israel. $f$ Med Virol 1988;24:19-25.

25 Walmus BF, Yow MD, Lester JW, Leeds L, Thompson PK, Woodward RM. Factors predictive of cytomegaloPK, Woodward RM. Factors predictive of cytomegalo-
virus immune status in pregnant women. $\mathcal{F}$ Infect Dis
$1988 ; 157: 172-7$.

26 Woodward CG, Thomlinson J, Hambling MH. Immunity to cytomegalovirus amongst pregnant women with differing racial backgrounds. Public Health 1987,101:329-32.

27 Cabau N, Labadie MD, Vesin C, Feingold J, Boue A. Seroepidemiology of cytomegalovirus infection during the first years of life in urban communities. Arch Dis Child 1979;54:286-90.

28 Grillner L, Strangert K. Restriction endonuclease analysis of cytomegalovirus DNA from strains isolated in day care centers. Pediatr Infect Dis 1986;5:184-7.

29 Nelson DB, Peckham CS, Pearl KN, Chin KS, Garrett AJ, Warren DE. Cytomegalovirus infection in day nurseries. Arch Dis Child 1987;62:329-32.

30 Adler $S$. The molecular epidemiology of cytomegalovirus transmission among children attending a day care center. transmission among children

31 Adler SP. Cytomegalovirus and child day care: evidence for an increased infection rate among day-care workers. $N$ Engl f Med 1989;321:1290-6.

32 Pass RF, Hutto C, Dee Lyon M, Cloud G. Increased rate of cytomegalovirus infection among day care centre workers. Pediatr Infect Dis 1990;9:465-70

33 Murph JR, Baron JC, Brown CK, Ebelhack CL, Bale JF. The occupational risk of cytomegalovirus infection among day-care providers. $\mathcal{F A M A} 1991 ; 265: 603-8$

34 Yow MD, Williamson DW, Leeds LJ, et al. Epidemiologic characteristics of cytomegalovirus infection in mothers and their infants. Am $f$ Obstet Gynecol 1988; 158:1189-95.

35 Stagno S, Pass RF, Cloud G, et al. Primary cytomegalovirus infection in pregnancy: incidence, transmission to fetus, and clinical outcome. $\mathcal{J A M A} 1986 ; 256$ : 1904-8.

36 Stagno $\dot{S}$, Reynolds $R$, Tsiantos A, et al. Cervical cytomegalovirus excretion in pregnant and nonpregnant women: suppression in early gestation. $\mathcal{F}$ Infect Dis 1975 ; 131:522-7.

37 Reynolds DW, Stagno S, Mosty TS. Maternal cytomegalovirus excretion and perinatal infection. $N$ Engl $f$ Med 1980;302:1073-6.

38 Davie R, Butler N, Goldstein H. From birth to seven: a report of the national child development study. London: Longman, 1972 .

39 Chamberlain R, Chamberlain G, Howlett B, Claireaux A. British Births 1970. London: Heinemann, 1975.

40 Hayes K, Danks DM, Gibas H, Jack I. Cytomegalovirus in human milk. N Engl F Med 1972;287:177-8.

41 Griffiths P, Baboonian C, Ashby D. The demographic characteristics of pregnant women infected with cytomegalovirus. Int $\mathcal{f}$ Epidemiol 1985;14:447-52. 